up-to-date than my last year's choice, Ayala and Kiger's Modern Genetics (Benjamin/Cummings, 1980) but I do not think that it is obviously better. I prefer Ayala and Kiger's somewhat less historical approach and their greater integration of molecular and Mendelian genetics, although I believe both should be taken much further. I still think there is much to be said in favour of Fristrom and Spieth's Principles of Genetics (Chiron/Blackwell

\section{Not quite Wilson}

\section{Michael Ashburner}

Cytogenetics: The Chromosome in Division, Inheritance and Evolution, 2nd Edn. By Carl P. Swanson, Timothy Merz and William J. Young. Pp.557. ISBN 0-13-196618-9. (Prentice-Hall: 1981.) $\$ 25.95$, £19.45. Cytogenetics: Plants, Animals, Humans. By Jurgen SchulzSchaeffer. Pp.446. ISBN 3-540-90467-0. (Springer-Verlag: 1981.) DM69, \$40.60.

A Distinguished cytologist of my acquaintance never ventures abroad without his copy of the third edition of E. B. Wilson's The Cell in Heredity and Development (Macmillan, 1925) under his arm, carefully preserved from the elements by a wrapping of plain brown paper. I fear that neither of the two textbooks of cytogenetics reviewed here will command such devotion 60 years hence. Both Swanson, Merz and Young (SMY) and Schulz-Schaeffer have written texts aimed, by and large, at an advanced undergraduate audience, though both hope that their volumes may be of use to more "advanced" researchers.

The books are not only similar in purpose, they are similar in the general extent of their coverage, treating such broad topics as the structure and function of chromosomes, the behaviour of chromosomes at mitosis and meiosis, chromosome aberrations and chromosomes in evolution in a reasonably conventional way. There is, it is true, a considerable difference in emphasis between SMY and Schulz-Schaeffer; the latter gives the cytogenetics of plants (especially cereals) particularly strong attention, whilst the former devotes more space to a consideration of evolutionary issues. It is, perhaps, for this reason that I am more naturally drawn to SMY and approached Schulz-Schaeffer more from the desire to know what new I could glean from it.

I began this review with an implicit comparison of these two books with E.B. Wilson's masterpiece. Part of the reason for Wilson's greatness (I speak of both book and man) was the regard and understanding he had of genetics. The signal failure of Schulz-Schaeffer stems, in
Scientific, 1980), last year's second choice, which adopts a much less conventional approach to the subject, and so my own list of recommended texts now includes all these three. Mays's book is neither good enough nor bad enough to warrant special mention but I am afraid I will have to warn my students off Pai and Marcus-Roberts.

D.J. Cove is Professor in the Department of Genetics at the University of Leeds.

my opinion, from the absence of any true integration of the "cyto-" and the "genetics". This book suffers too from a lack of balance in the presentation of the material and from the author's inability to distinguish between the trivial and the lasting. Perhaps I should illustrate these harsh criticisms. A very common class of chromosome aberration, both in natural and experimental populations, is the inversion. Inversions have the property that, when heterozygous, they suppress genetic recombination. The precise mechanisms by which this suppression of recombination is achieved were elucidated by Sturtevant and Beadle in 1936, and their paper (Genetics 21, 554-604) is one of the most elegant in genetics. Not only does Schulz-Schaeffer fail to give a summary of this work (let alone reference it) but he wastes his reader's time with such trivia as the "fact" that "twenty seven different autosomal inversions have been reported from three different localities in Bulgaria in the mosquito species Anopheles messeae".

A second example of the lack of balance in this book may not be amiss. A paragraph (p.294) discussing somatic crossing over includes the statement that "soybean seems to be an ideal object for the study of somatic crossing over'. This may well be so, but it is rather an eccentric statement to make when the detailed and sophisticated studies of mitotic crossing over (as it should be called) in both yeast and Drosophila have virtually been ignored.

The lack of balance that I see in this textbook is serious: not only will it mislead the student but it will also undermine the confidence of other readers who might otherwise seek from it new information. There is, not surprisingly, much in SchulzSchaeffer that is new to me, yet I am reluctant to take anything at face value from an author who awards Francis Crick a knighthood (trivial in itself, perhaps, but a minor irritation) and who has, at least on occasion, clearly not consulted his original references. His account of parthenogenesis in aphids is but a poor paraphrase of White's review in the third edition of Animal Cytology and Evolution, and I see no signs of any attempt to look at the original data or take into account subsequent studies.

The second textbook, that by SMY, is far better. Although the second edition of a text first published in 1967, it is really the successor of Swanson's Cytology and Cytogenetics published by Macmillan ten years before that. Not only have SMY made a reasonably successful job of integrating the cytology and genetics (though even here I think Swanson did better in 1957) but they have also stamped upon the whole volume an evolutionary perspective that generates an impression of intellectual coherence. There is, however, one area of weakness in this book: that is in the various discussions of molecular cytogenetics. Not only is this subject treated, to my mind, in a rather oversimplified manner but the authors are too naive, accepting at face value some of the more speculative of models whose very authors, I am sure, would shudder to see exhumed in student text.

Michael Ashburner is a Reader in the Department of Genetics, University of Cambridge.

\section{Citron pressé?}

\section{P.A. Lawrence}

The Genetic Basis of Development. By Alistair D. Stewart and David M. Hunt. Pp. 221. Hbk ISBN 0-216-91161-3; pbk ISBN 0-216-91160-5. (Blackie/Wiley: 1982.) Hbk £18.95, \$27.95; pbk £8.95.

THE genetic approach to developmental biology can be fun and ought to be popular. But embryology is traditionally a soft subject that has often been closer to theology than science, while genetics has always been hard and numerological. Which may explain why, in the past, practitioners of the two disciplines have understood each other little and have rarely collaborated to solve biological problems. This makes no sense at all as genes are there to provide materials and information to construct and maintain animals. Genes and their products ought therefore to be at the heart of embryology - which is just where Stewart and Hunt perceive them to be.

Their aim was to write a brief embryological text from the geneticist's view point, and the result is a usefully analytical account. It is also up to date and breaks with the common practice (especially in embryology) of beating a new textbook out of older ones. In short, the authors have used the primary literature as their source. This may explain why the book is often tricky - especially for the "advanced undergraduate" for whom it is written. And also why it is too much of a review, being strong on lists of experiments and results and weak on explanation. A good example is the description of the bithorax complex of Drosophila. This locus is an illuminating link between genetics and development, as it appears that the elements of the locus are specifically deployed in developing segments. 